\title{
Serum DHEA-S levels could be used as a comparable diagnostic test to assess the pubertal growth spurt in dentofacial orthopedics
}

V. Anusuya ${ }^{14^{*}}$ (D, Amit Nagar ${ }^{2}$, Pradeep Tandon ${ }^{2}$, G. K. Singh ${ }^{2}$, Gyan Prakash Singh ${ }^{2}$ and A. A. Mahdi ${ }^{3}$

\begin{abstract}
Background: Pubertal growth spurt assessment guides the timing of intervention for correcting the skeletal discrepancies in dentofacial orthopedics. Serum hormones are being studied for the skeletal age assessment to avoid unnecessary radiographic exposure. The present study is to evaluate the relationship of serum hormones dehydroepiandrosterone-sulfate (DHEA-S), insulin-like growth factor (IGF-1), and cervical vertebral stages (CS stages) in the skeletal age assessment of orthodontics patients around the circumpubertal age.

Methods: A total of ninety subjects with age ranging from 7 to 21 years were selected and divided into two groups based on the sex (45 males, 45 females). They were further distributed in each group based on the six CS stages determined from the lateral cephalogram. Blood samples from each subject were collected to evaluate the serum DHEA-S and IGF-1 levels by using the enzyme-linked immunosorbent assay (ELISA). Collected data were analyzed in SPSS software with a test of normalcy, unpaired $t$ test, and one-way analysis of variance (ANOVA) followed by the least significant difference (LSD) post hoc comparison test and univariate regression analysis.

Results: The highest mean serum hormone levels were found in CS 4 in group A (male) and CS 3 in group B (female). ANOVA results showed that there was a significant difference in the serum hormone levels among the different CS stages in both the groups for both the hormones. Statistically, a significant difference was found between each CS stages for both the hormones except in the DHEA-S levels between CS 5 and CS 6.

Conclusions: The mean serum DHEA-S levels followed a typical pattern from the CS 1 till CS 6 which was comparable and similar to the mean serum IGF-1 levels in respect to CS stages. Thus, serum DHEA-S levels could be used as a possible diagnostic test for the assessment of the skeletal pubertal growth spurt in dentofacial orthopedics.
\end{abstract}

Keywords: Serum DHEA-S, IGF-1, CS stages, Skeletal growth, Cephalometrics, Growth assessment, Biomarker

\footnotetext{
*Correspondence: vanusuya91@gmail.com

'Department of Dentistry, All India Institute of Medical Sciences,

Bhubaneswar, Odisha 751019, India

${ }^{4}$ Tamilnadu, India

Full list of author information is available at the end of the article
}

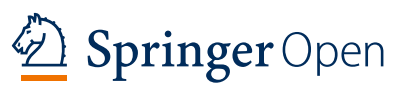

(c) The Author(s). 2020 Open Access This article is licensed under a Creative Commons Attribution 4.0 International License which permits use, sharing, adaptation, distribution and reproduction in any medium or format, as long as you give appropriate credit to the original author(s) and the source, provide a link to the Creative Commons licence, and indicate if changes were made. The images or other third party material in this article are included in the article's Creative Commons licence, unless indicated otherwise in a credit line to the material. If material is not included in the article's Creative Commons licence and your intended use is not permitted by statutory regulation or exceeds the permitted use, you will need to obtain permission directly from the copyright holder. To view a copy of this licence, visit http://creativecommons.org/licenses/by/4.0/. 


\section{Background}

The age of an individual is one of the important determinant factors in the treatment planning of malocclusion. It guides the orthodontist to allocate the growthrelated treatment modalities in growing individuals. Among the different biological ages, skeletal age determination using hand-wrist radiographs is the gold standard for the assessment of overall skeletal growth status and the craniofacial structures [1]. Skeletal age reveals the present growth status as well as the remaining skeletal growth. In dentofacial orthopedics, treatment timing is mainly based on the pubertal growth spurts [2]. Skeletal class III malocclusion is best corrected during the pre-pubertal stage and skeletal class II during the pubertal growth spurt [3-6]. Thus, skeletal age determination is crucial to start the dentofacial interception at the right time to correct the skeletal deficiencies, in turn, to get the best possible treatment results [7].

Various tools are available for skeletal age determination, being gold standard; hand-wrist radiograph needs additional radiograph to be taken in the orthodontic patients [8-12]. Thus, cervical stages determined from the lateral cephalogram are routinely used for this purpose in patients undergoing orthodontic treatment [13]. Recently, biomarkers are evaluated to determine the circumpubertal growth stages. Hormones and bio-molecules evaluated from the serum, saliva, and urine were well reported to determine the skeletal age [14-17]. Serum IGF-1 has already been studied and established as a biomarker for the skeletal pubertal growth assessment $[18,19]$. But as far as IGF-1 is concerned, the availability of laboratories for the testing and the cost are high. So, an alternative which could be easily available and cost-effective will be a better biomarker to use in day-to-day practice.

Puberty and pubertal growth spurt occur as a manifestation of changes and a delicate balance between various hormones, especially the growth and sex hormones [20]. It has been observed that the synchronized hormonal events take place even before the growth spurt in puberty. Adrenarche is one of the events, where there is an onset of production of DHEA and DHEA-S from the zona reticularis of the adrenal gland [21]. DHEA is the most abundant circulating steroid which gets sulfated into DHEA-S by sulfatases [22]. DHAE-S, an important factor in bone accretion, regulates bone mineral density and bone deposition during growth. In combination with carnitine, it promotes alkaline phosphatase activity and collagen I synthesis. Another function is to stimulate IGF-1 which in turn stimulates estrogen production that results in enhanced stimulation of the bone formation [23-25].

The role of DHEA-S in puberty, in the skeletal growth regulation, and also the DHEA-S diagnostic test which is more commonly used led us to this present study. It was to test the null hypothesis that there is no relationship exists between the serum DHEA-S levels and CS stages determined from the lateral cephalogram in the subjects of circum-pubertal age, in addition the relationship of IGF-1 and DHEA-S levels in different CS stages.

\section{Material and methods}

The present study was conducted in patients with an age range between 7 to 21 years, with mean age of $13.65 \pm$ 4.01 years, who were enrolled for orthodontic treatment in the Department of Orthodontics \& Dentofacial Orthopedics in collaboration with the Department of Biochemistry, King George Medical University, Lucknow, Uttar Pradesh, India. All the subjects were apparently normal and healthy as per the Revised 2014 IAP Growth charts for height, weight, and body mass index (BMI) between 3rd and 97th percentiles of standards [26], which ensured good nutritional status and adequate growth velocity at the proper time. Subjects with a history of bleeding disorders, syndromes, chronic medication, hormone replacement therapy, and hormonal disorders and a history of trauma or surgery or anomaly in the area of cervical vertebrae were excluded from the study. Ethical approval was obtained from the institutional ethical committee (project no: 72nd ECM II-B-IMR/P2). After obtaining the written consent, demographic data were recorded individually for the subjects who fulfilled the inclusion and exclusion criteria.

The sample size was calculated, with $95 \%$ confidence interval, $80 \%$ power, $5 \%$ significance level, and less than $20 \mathrm{ng} / \mathrm{ml}$ of error of estimation by keeping the mean IGF-1 serum level of $298.6 \mathrm{ng} / \mathrm{ml}$ with a standard deviation of $85 \mathrm{ng} / \mathrm{ml}$ in cervical vertebrae maturation (CVM) stage 2 patients [18]. It was found that 69 is the minimum needed sample. But it was inflated as a total sample of 90 for the convenience of distribution in each group. Subjects were divided into 2 groups based on sex-group A (male) and group B (female), each consisting of 45 subjects. In each group, further distribution was done based on the six CS stages of the modified CVM stage given by Baccetti et al. [13].

Digital lateral cephalometric radiographs (Kodak Tmat Blue; Kodak Limited, Hemel Hempstead, Hertfordshire, UK) were recorded by positioning the subjects in a cephalostat at natural head position with the X-ray machine parameters kept at $8 \mathrm{~mA}$ and 80 kvp. Subjects were instructed to maintain the centric occlusion with lips at repose during the radiographic exposure. All the radiographs were recorded by the same technician. The radiographs were given random numbers after retrieval; thus, the examiner was blinded about the details of the subjects to avoid bias. The superior, inferior, posterior, and anterior borders of the second, third, and fourth 
cervical vertebrae were traced for cervical staging. Two examiners (A.V and R.A) independently determined the CS stages using the method described by Baccetti et al. [13]. Then, the respective lateral cephalograms were reanalyzed by the same examiners after $6-8$ weeks. Using Kappa statistics, the interexaminar agreement was found to be $90.0 \%$ and intraexaminer were $91.2 \%$ and $91.9 \%$ for A.V and R.A respectively with a statistically significant $(p=0.001)$ agreement.

On the same day, blood samples were collected by venipuncture, between 9:00 h and noon. In our study, the protocol for phlebotomy-(the drawing of blood) was adapted from the World Health Organization (WHO) guidelines [27]. About $3 \mathrm{ml}$ of blood was drawn using the closed blood sampling system by the use of a hypodermic needle and syringe technique from a peripheral vein preferably median cubital vein in the antecubital area. Blood was transferred to the sterile blood collection tubes coated with a clot activator and placed in a leak-proof transporter. Each of the samples was given random numbers and sent to the laboratory. Once received in the laboratory, the samples were allowed to clot at room temperature for $1 \mathrm{~h}$ after which they were centrifuged for $10 \mathrm{~min}$ at approximately $1000 \mathrm{rpm}$ for separation of serum. Using the clean pipette technique, clearly defined separation of serum was aliquoted by disposable pipette tips $(1000 \mu \mathrm{L})$ into plastic Eppendorf disposable tubes. Serum samples were then labeled and stored in a freezer at $-80{ }^{\circ} \mathrm{C}$. Serum IGF- 1 and DHEA$\mathrm{S}$ levels were assessed by enzyme-linked immunosorbent assay test (human IGF-1 and human DHEA-S ELISA Kit, SRB, Shanghai, China).

\section{Statistical analysis}

Data collected was prepared to analyze in the SPSS software (Statistical Package for the Social Sciences, version.25, IBM). Shapiro-Wilk test was applied to test the normality. Based on the distribution, further descriptive statistics were used. The unpaired $t$ test was used to compare the mean difference between two groups, and within the group comparison was done by using oneway ANOVA followed by LSD post hoc test. Univariate regression analysis was done to evaluate the correlation between the hormones and the CS stages. The $p$ value of $<0.05$ was set as statistically significant.

\section{Results}

The data was found to be normally distributed; thus, an unpaired $t$ test was used to compare the mean serum hormone levels between the two groups in each CS stage (Table 1). Serum DHEA-S levels were significantly higher in all the CS stages of group A except CS 2 and CS 3 ( $p=0.001$ and 0.0001), whereas serum IGF-1 was found to be significantly higher in all CS stages except CS 1 and CS 3 ( $p=0.0001)$. The peak of both serum hormone levels were found to be in CS 4 in group A and CS 3 in group B. The highest mean \pm SD serum DHEA-S level was $685.33 \pm 39.11 \mathrm{nmol} / \mathrm{ml}$ in group A and $578.12 \pm 13.76 \mathrm{nmol} / \mathrm{ml}$ in group $\mathrm{B}$. The highest mean \pm SD serum IGF-1 level was $538.32 \pm 32.31 \mathrm{ng} / \mathrm{ml}$ in group A and $460.38 \pm 13.49 \mathrm{ng} / \mathrm{ml}$ in group $B$.

ANOVA results showed that there was a significant difference in the serum hormone level among the different CS stages in both the groups for both the hormones (Table 2). In group A, the LSD post hoc test revealed

Table 1 Comparison of mean and standard deviation of IGF-1 $(\mathrm{ng} / \mathrm{ml})$ and DHEA-S $(\mathrm{nmol} / \mathrm{ml})$ levels among CS stages between group A and group B

\begin{tabular}{|c|c|c|c|c|}
\hline \multirow{2}{*}{$\begin{array}{l}\text { CS stages }(\boldsymbol{n}= \\
M, F)\end{array}$} & \multirow[t]{2}{*}{ Hormone } & \multirow{2}{*}{$\begin{array}{l}\text { Group A (male) } \\
\text { Mean } \pm \text { SD }\end{array}$} & \multirow{2}{*}{$\begin{array}{l}\text { Group B (female) } \\
\text { Mean } \pm \text { SD }\end{array}$} & \multirow[t]{2}{*}{$\boldsymbol{p}$ value } \\
\hline & & & & \\
\hline \multirow[t]{2}{*}{$\operatorname{CS} 1(n=8,8)$} & IGF-1 & $164.22 \pm 12.36$ & $197.19 \pm 8.99$ & $0.000^{* * *}$ \\
\hline & DHEA-S & $232.17 \pm 15.20$ & $185.03 \pm 18.13$ & $0.000 * * *$ \\
\hline \multirow[t]{2}{*}{$\operatorname{CS} 2(n=8,8)$} & IGF-1 & $256.06 \pm 15.04$ & $232.50 \pm 9.79$ & $0.002^{* *}$ \\
\hline & DHEA-S & $295.40 \pm 14.22$ & $344.91 \pm 30.77$ & $0.001 * *$ \\
\hline \multirow[t]{2}{*}{$\operatorname{CS} 3(n=7,7)$} & IGF-1 & $332.31 \pm 16.27$ & $460.38 \pm 13.49$ & $0.000^{* * *}$ \\
\hline & DHEA-S & $451.77 \pm 34.20$ & $578.12 \pm 13.76$ & $0.000 * * *$ \\
\hline \multirow[t]{2}{*}{ CS $4(n=7,7)$} & |GF-1 & $538.32 \pm 32.31$ & $228.33 \pm 8.96$ & $0.000^{* * *}$ \\
\hline & DHEA-S & $685.33 \pm 39.11$ & $308.32 \pm 7.68$ & $0.000 * * *$ \\
\hline \multirow[t]{2}{*}{$\operatorname{CS} 5(n=7,7)$} & IGF-1 & $212.76 \pm 4.01$ & $206.31 \pm 6.77$ & $0.050^{*}$ \\
\hline & DHEA-S & $351.13 \pm 29.80$ & $229.70 \pm 17.82$ & $0.000 * * *$ \\
\hline \multirow[t]{2}{*}{ CS $6(n=8,8)$} & $\mid G F-1$ & $184.38 \pm 12.84$ & $175.27 \pm 6.12$ & $0.920^{\mathrm{ns}}$ \\
\hline & DHEA-S & $253.38 \pm 22.14$ & $216.98 \pm 15.44$ & $0.002^{* *}$ \\
\hline
\end{tabular}

$p$ value is significant at the 0.05 level

ns non-significant

${ }^{*} p<0.05,{ }^{* *} p<0.01,{ }^{* * *} p<0.001$ 
Table 2 Comparison of serum hormone levels within the groups among the CS stages (ANOVA)

\begin{tabular}{|c|c|c|c|c|c|c|c|}
\hline Hormone & CS 1 & CS 2 & CS 3 & $\operatorname{CS} 4$ & CS 5 & CS 6 & $p$ value \\
\hline IGF-1 (group A) & $164.22 \pm 12.36$ & $256.06 \pm 15.04$ & $332.31 \pm 16.27$ & $538.32 \pm 32.31$ & $212.76 \pm 4.01$ & $184.38 \pm 12.84$ & $0.000^{* * * *}$ \\
\hline DHEA-S (group A) & $232.17 \pm 15.20$ & $295.40 \pm 14.22$ & $451.77 \pm 34.20$ & $685.33 \pm 39.11$ & $351.13 \pm 29.80$ & $253.38 \pm 22.14$ & $0.000^{* * *}$ \\
\hline IGF-1 (group B) & $197.19 \pm 8.99$ & $232.50 \pm 9.79$ & $460.38 \pm 13.49$ & $228.33 \pm 8.96$ & $206.31 \pm 6.77$ & $175.27 \pm 6.12$ & $0.000 * * *$ \\
\hline DHEA-S (group B) & $185.03 \pm 18.13$ & $344.91 \pm 30.77$ & $578.12 \pm 13.76$ & $308.32 \pm 7.68$ & $229.70 \pm 17.82$ & $216.98 \pm 15.44$ & $0.000^{* * *}$ \\
\hline
\end{tabular}

$p$ value is significant at the 0.05 level

ns non-significant

${ }^{*} p<0.05,{ }^{* *} p<0.01,{ }^{* * *} p<0.001$

that there was a significant difference in the serum IGF1 levels in between each CS stages (Table 3). The change in the hormone levels was a significant increase from the CS 1 to CS $2(p<0.001)$, then CS 2 to CS $3(p<0.001)$, from CS 3 to CS $4(p<0.001)$, thereafter decrease till CS $6(p<0.001)$. The same pattern was also found in the DHEA-S hormone levels (Table 3). In group B, IGF1 hormone levels increased significantly from the CS 1 till CS $3(p<0.001)$ to the highest and then significantly decreased till the CS 6 (Table 4). DHEA-S hormone levels followed a similar pattern with significant changes except in stages CS 5 and CS 6 (Table 4).

Table 5 summarized the comparison of mean and standard deviation of BMI in different CS stages between group A and group B. Table 6 outlines the results of univariate regression analysis. When the CS stages were combined as pre-pubertal (CS 1 and 2), pubertal (CS 3 and 4), and post-pubertal (CS 5 and 6) and analyzed, IGF-1 hormone levels are more likely to increase in pubertal stages compared to pre-pubertal stages $(\mathrm{OR}=$ 1.010); also, DHEA-S levels were more likely to hike in pubertal stages compared to pre-pubertal stages $(\mathrm{OR}=$ 1.004) and both were statistically significant (Table 6).

\section{Discussion}

The skeletal deficiencies are intercepted and treated well when the intervention is given at the right time, which focuses mainly on the pubertal growth spurt. The goal of the present study was to evaluate whether serum DHEA-S could be used as a biomarker for assessing skeletal maturation during the pubertal growth spurt. Based on the cervical stages of Baccetti et al. [13] and cervical vertebrae maturation indicator, the samples were divided among the two groups. Thus, the relationship between serum DHEA$S$ levels and the CS stages could be used as a possible predictor for the assessment of pubertal growth spurt. In our study, we have taken a parallel comparator, i.e., serum IGF-1 levels, which is an established biomarker for the same purpose. Thus, the serum IGF-1 levels were measured in each stage, and its change in levels with each CS stage was compared to DHEA-S level, which would reassure the obtained results.

Among the CS stages, the highest serum DHEA-S levels were observed in the CS 3 in group B and CS 4 in group $\mathrm{A}$, and the values were $578.12 \pm 13.76 \mathrm{nmol} / \mathrm{ml}$ and $685.33 \pm 39.11 \mathrm{nmol} / \mathrm{ml}$ respectively (Table 1 ). This was in contrast with the study done by Srinivasan and

Table 3 Comparison of IGF-1 and DHEA-S levels in between the CS stages using the LSD test in group A

\begin{tabular}{|c|c|c|c|c|c|c|c|}
\hline \multirow{2}{*}{$\begin{array}{l}\text { Dependent } \\
\text { variable }\end{array}$} & \multirow{2}{*}{$\begin{array}{l}\text { (I) CS } \\
\text { stage }\end{array}$} & \multirow{2}{*}{$\begin{array}{l}(\mathrm{J}) \\
\mathrm{CS} \\
\text { stage }\end{array}$} & \multirow{2}{*}{$\begin{array}{l}\text { Mean } \\
\text { difference } \\
(I-J)\end{array}$} & \multirow{2}{*}{$\begin{array}{l}\text { Std. } \\
\text { error }\end{array}$} & \multirow[t]{2}{*}{ Sig. } & \multicolumn{2}{|c|}{ 95\% confidence interval } \\
\hline & & & & & & Lower bound & Upper bound \\
\hline \multirow[t]{6}{*}{ |GF-1 } & 1 & 2 & -91.84 & 8.68 & $0.000^{* * *}$ & -109.40 & -74.27 \\
\hline & 2 & 3 & -76.24 & 8.98 & $0.000^{* * *}$ & -94.42 & -58.06 \\
\hline & 3 & 4 & -206.01 & 9.28 & $0.000^{* * *}$ & -224.79 & -187.24 \\
\hline & 4 & 5 & 325.56 & 9.28 & $0.000^{* * *}$ & 306.78 & 344.33 \\
\hline & 5 & 6 & 28.38 & 8.98 & $0.003^{* * *}$ & 10.20 & 46.56 \\
\hline & 6 & 1 & 20.15 & 8.68 & $0.026^{*}$ & 2.59 & 37.71 \\
\hline \multirow[t]{6}{*}{ DHEA-S } & 1 & 2 & -63.236 & 13.39 & $0.000^{* * *}$ & -90.33 & -36.13 \\
\hline & 2 & 3 & -156.366 & 13.86 & $0.000^{* * *}$ & -184.41 & -128.31 \\
\hline & 3 & 4 & -233.559 & 14.32 & $0.000^{* * *}$ & -262.52 & -204.59 \\
\hline & 4 & 5 & 334.198 & 14.32 & $0.000^{* * *}$ & 305.23 & 363.16 \\
\hline & 5 & 6 & 97.745 & 13.86 & $0.000^{* * *}$ & 69.69 & 125.79 \\
\hline & 6 & 1 & 21.217 & 13.39 & $0.121^{\mathrm{ns}}$ & -5.87 & 48.31 \\
\hline
\end{tabular}

The mean difference is significant at the 0.05 level

ns non-significant

${ }^{*} p<0.05,{ }^{* *} p<0.01,{ }^{* * *} p<0.001$ 
Table 4 Comparison of IGF-1 and DHEA-S levels in between the CS stages using the LSD test in group B

\begin{tabular}{|c|c|c|c|c|c|c|c|}
\hline \multirow{2}{*}{$\begin{array}{l}\text { Dependent } \\
\text { variable }\end{array}$} & \multirow{2}{*}{$\begin{array}{l}\text { (I) CS } \\
\text { stage }\end{array}$} & \multirow{2}{*}{$\begin{array}{l}(\mathrm{J}) \\
\text { CS } \\
\text { stage }\end{array}$} & \multirow{2}{*}{$\begin{array}{l}\text { Mean } \\
\text { difference } \\
(I-J)\end{array}$} & \multirow{2}{*}{$\begin{array}{l}\text { Std. } \\
\text { error }\end{array}$} & \multirow[t]{2}{*}{ Sig. } & \multicolumn{2}{|c|}{ 95\% confidence interval } \\
\hline & & & & & & Lower bound & Upper bound \\
\hline \multirow[t]{6}{*}{ |GF-1 } & 1 & 2 & -35.31 & 4.63 & $0.000^{* * *}$ & -44.69 & -25.94 \\
\hline & 2 & 3 & -227.87 & 4.79 & $0.000^{* * *}$ & -237.57 & -218.17 \\
\hline & 3 & 4 & 232.04 & 4.95 & $0.000^{* * *}$ & 222.02 & 242.06 \\
\hline & 4 & 5 & 22.02 & 4.95 & $0.000^{* * *}$ & 12.00 & 32.04 \\
\hline & 5 & 6 & 31.03 & 4.79 & $0.003^{* * *}$ & 21.33 & 40.74 \\
\hline & 6 & 1 & -21.91 & 4.63 & $0.026^{*}$ & -31.28 & -12.54 \\
\hline \multirow[t]{6}{*}{ DHEA-S } & 1 & 2 & -159.87 & 9.47 & $0.000^{* * *}$ & -179.03 & -140.71 \\
\hline & 2 & 3 & -233.21 & 9.80 & $0.000^{* * *}$ & -253.05 & -213.38 \\
\hline & 3 & 4 & 269.80 & 10.12 & $0.000^{* * *}$ & 249.32 & 290.29 \\
\hline & 4 & 5 & 78.61 & 10.12 & $0.000^{* * *}$ & 58.13 & 99.09 \\
\hline & 5 & 6 & 12.72 & 9.80 & $0.202^{\text {ns }}$ & -7.10 & 32.55 \\
\hline & 6 & 1 & 31.94 & 9.47 & $0.002^{* *}$ & 12.78 & 51.10 \\
\hline
\end{tabular}

The mean difference is significant at the 0.05 level

ns non-significant

${ }^{*} p<0.05,{ }^{* *} p<0.01,{ }^{* * *} p<0.001$

Premkumar [28]. In their study, subjects were divided as pre-pubertal, pubertal, and adult groups based on the hand-wrist radiographs and the sample consisted of subjects with age ranges from 7 to 30 . The highest mean \pm SD serum hormone level was observed in the adult group. As supported by Kroboth et al. study [24], the DHEA-S levels peak around 20-30 years of age then decreases gradually, which would be the reason for this difference in both the studies. In our study, maximum age limit taken was 21 years and grouping was focused mainly on the CS stages which are clinically related to the maxillary and mandibular growth. Though the previous study found a significant difference between prepubertal, pubertal, and adult groups, they were not in respect with CS stages from lateral cephalogram. The peak value observed in our study was in consistent with the first chronological peak DHEA-S values observed in the previous study [29].

Table 5 Comparison of mean and standard deviation of BMI in different CS stages between group A and group B

\begin{tabular}{llll}
\hline $\begin{array}{l}\text { CS stages } \\
(n=\mathrm{M}, \mathrm{F})\end{array}$ & $\begin{array}{l}\text { Group A (male) } \\
\text { Mean } \pm \text { SD }\end{array}$ & $\begin{array}{l}\text { Group B (female) } \\
\text { Mean } \pm \text { SD }\end{array}$ & $\begin{array}{l}p \\
\text { value }\end{array}$ \\
\hline Stage 1 $(n=8,8)$ & $17.9 \pm 1.7$ & $17.2 \pm 1.4$ & $0.40^{\text {ns }}$ \\
Stage 2 $(n=8,8)$ & $19.3 \pm 1.0$ & $20.1 \pm 1.2$ & $0.17^{\text {ns }}$ \\
Stage 3 $(n=7,7)$ & $17.8 \pm 1.6$ & $20.1 \pm 1.4$ & $0.019^{*}$ \\
Stage 4 $(n=7,7)$ & $21.4 \pm 0.9$ & $19.0 \pm 1.1$ & $0.001^{* *}$ \\
Stage 5 $(n=7,7)$ & $23.3 \pm 2.0$ & $20.7 \pm 1.9$ & $0.035^{*}$ \\
Stage 6 $(n=8,8)$ & $22.3 \pm 2.2$ & $21.3 \pm 1.5$ & $0.29^{\text {ns }}$ \\
\hline
\end{tabular}

$p$ value is significant at the 0.05 level

ns non-significant

${ }^{*} p<0.05,{ }^{* *} p<0.01$, ${ }^{* *} p<0.001$
Mean serum hormone levels were found to be least in the CS 6 in females and CS 1 in the males. But from the CS 1 stage, there was a significant gradual increase in the hormone levels in each CS stage until it reaches the highest value in respective groups. After reaching the peak value, there was a decrease in the serum levels. In group A, a decrease was found from CS 4 to CS 5 and to CS 6, whereas in group B, from CS 3 to CS 4, CS 4 to CS 5, and to CS 6. The peak values of serum hormones observed in the CS stages of respective groups are consistent with the pubertal growth spurts of the respective groups, i.e., CS 3 in females and CS 4 in males [13]. When accounting the sexual dimorphism, significant difference was found between the males and females in the DHEA-S levels. This could be due to the influence and interaction of difference in the sexual maturity, difference in the BMI (Table 5), and the growth pattern in the males and females than gender difference itself [30-32].

While observing the serum IGF-1 levels, the highest mean serum IGF-1 level was found to be in CS 4 in group $\mathrm{A}$ and CS 3 in group B, with values of $538.32 \pm 32.31 \mathrm{ng} /$ $\mathrm{ml}$ and $460.38 \pm 13.49 \mathrm{ng} / \mathrm{ml}$ respectively, with a significant sexual dimorphism observed in each CS stage. This was consistent with the results of the previous studies [14, 18 ], but the values were in different ranges from the previous study which could be due to difference in the ethnicity of the subjects studied. People from different ethnicity have a different range of normal serum IGF-1 hormone levels. The change in IGF-1 values in each stage followed a typical pattern which was also found in the serum DHEA-S levels (Fig. 1 and Fig. 2). In addition, the difference between the hormone levels in each CS stage was 
Table 6 Univariate regression analysis of relationship of IGF-1 and DHEA-S with CS stages

\begin{tabular}{|c|c|c|c|c|c|c|c|c|c|}
\hline \multicolumn{10}{|c|}{ Parameter estimates } \\
\hline \multirow[t]{2}{*}{ CS stages } & & \multirow[t]{2}{*}{ B } & \multirow{2}{*}{$\begin{array}{l}\text { Std. } \\
\text { error }\end{array}$} & \multirow[t]{2}{*}{ Wald } & \multirow[t]{2}{*}{ Df } & \multirow[t]{2}{*}{ Sig. } & \multirow{2}{*}{$\begin{array}{l}\text { Exp } \\
\text { (B) }\end{array}$} & \multicolumn{2}{|c|}{ 95\% confidence interval for $\operatorname{Exp}(B)$} \\
\hline & & & & & & & & Lower bound & Upper bound \\
\hline \multirow[t]{2}{*}{ Pubertal } & DHEA & 0.004 & 0.002 & 5.517 & 1 & $0.019^{*}$ & 1.004 & 1.001 & 1.007 \\
\hline & IGF & 0.010 & 0.003 & 8.628 & 1 & $0.003^{* *}$ & 1.010 & 1.003 & 1.016 \\
\hline \multirow[t]{2}{*}{ Post-pubertal } & DHEA & -0.006 & 0.003 & 4.691 & 1 & $0.030^{*}$ & 0.994 & 0.988 & 0.999 \\
\hline & IGF & -0.012 & 0.006 & 4.884 & 1 & $0.027^{*}$ & 0.988 & 0.977 & 0.999 \\
\hline
\end{tabular}

The reference category is pre-pubertal

$p$ value is significant at the 0.05 level

ns non-significant

${ }^{*} p<0.05,{ }^{* *} p<0.01,{ }^{* * *} p<0.001$

statistically significant with a clear interval in both groups. A univariate regression analysis was done after combining the CS 1 and CS 2 as pre-pubertal, CS 3 and CS 4 as pubertal, and CS 5 and CS 6 as post-pubertal (Table 6). Compared to the pre-pubertal stage values, the pubertal stage was more likely to be predicted by both the hormones and it was statistically significant $(p<0.05)$ with the odds ratio that was almost same for both the hormones. Thus, it supported the use of the serum DHEA-S hormone levels to predict the different circumpubertal stages.

The serum DHEA-S levels followed a pattern similar to the pubertal growth curve and to the serum IGF-1 level. The peak in the graph was consistent with the pubertal-skeletal growth accelerations. In addition, the regression analysis revealed the possible association with the different stages. But the only difference was the comparable difference found in the serum DHEA-S levels between the CS 5 and CS 6 in group B which may reduce the use of DHEA-S levels to assess the CS 5 and CS 6 stages. Otherwise, the findings support the definitive relationship between the serum DHEA-S levels and the CS stages. Hence, this relationship between the serum DHEA-S and the CS stages among the circumpubertal age rejected the null hypothesis. The preliminary work done with a relatively small sample size in a cross-sectional study design could be a possible set back of our study, which needs further prospective analysis in a larger population.

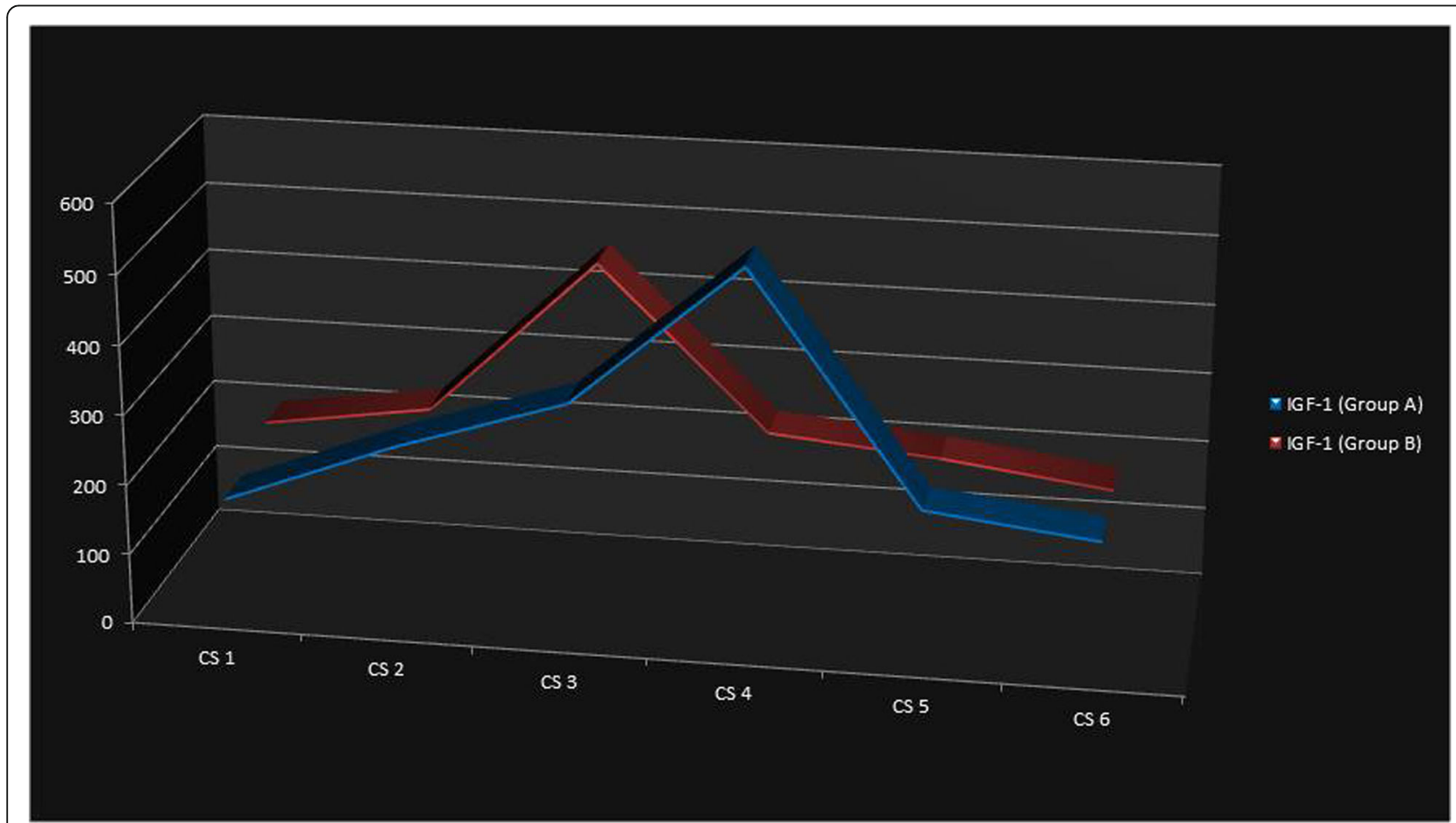

Fig. 1 Serum IGF-1 levels in each CS stage in group A and group B 


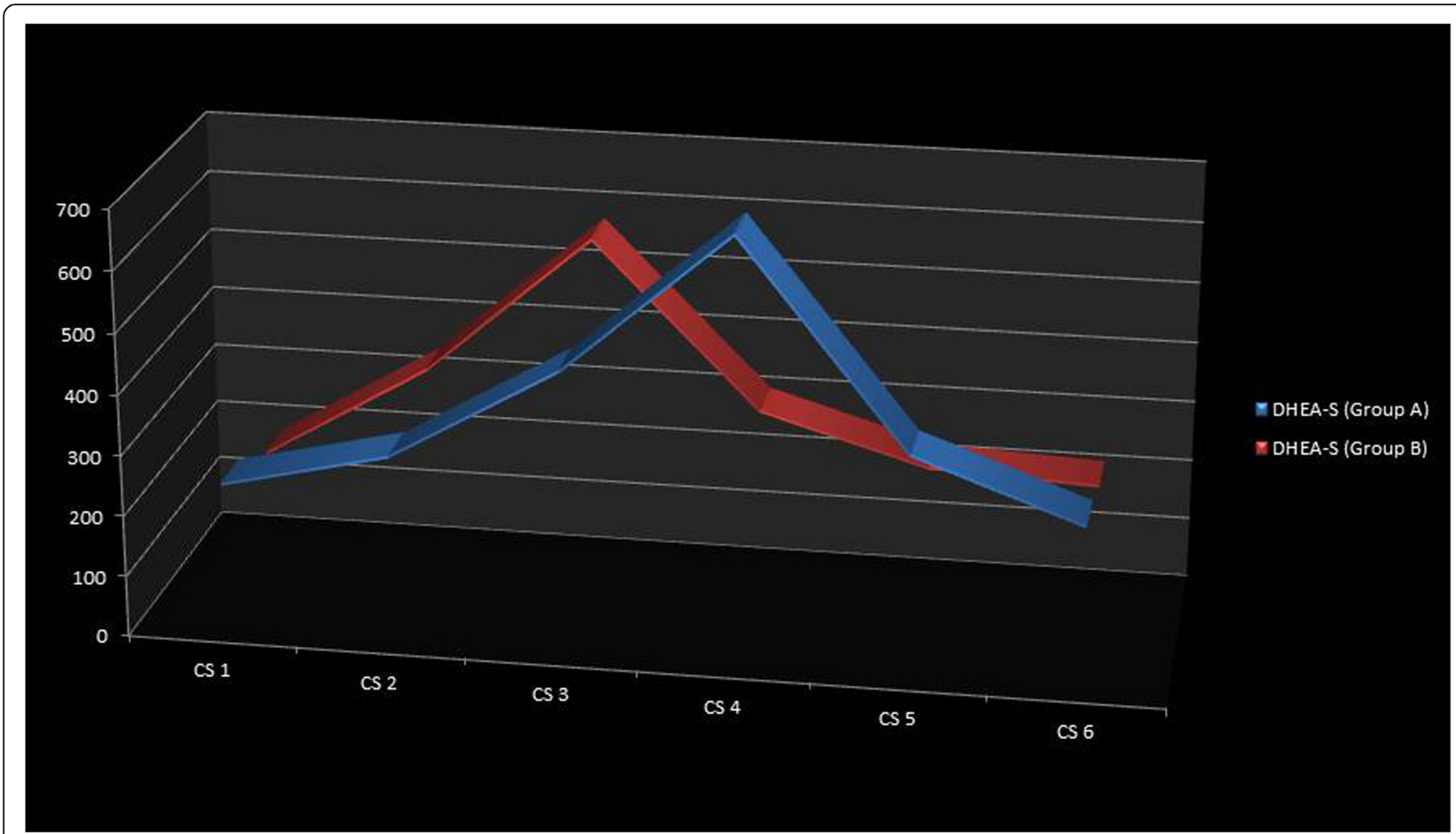

Fig. 2 Serum DHEA-S levels in each CS stage in group A and group B

\section{Conclusion}

1. The peak serum DHEA-S level was found in CS 3 stage in females and in CS 4 in males with values $578.12 \pm 13.76 \mathrm{nmol} / \mathrm{ml}$ and $685.33 \pm 39.11 \mathrm{nmol} /$ $\mathrm{ml}$ respectively.

2. There was a significant difference in the mean serum DHEA-S levels in between each CS stages of both the groups except CS 5 and CS 6 in the females.

3. A definite relationship was found between the serum DHEA-S levels and the CS stages from the lateral cephalogram.

4. The mean serum DHEA-S levels followed a typical pattern from the CS 1 till CS 6 which was comparable and similar with the mean serum IGF-1 levels and pubertal growth curve.

5. Thus, serum DHEA-S levels could be used as a possible diagnostic test for the assessment of the pubertal growth spurt in dentofacial orthopedics.

\section{Abbreviations}

DHEA-S: Dehydroepiandrosterone-sulfate; IGF-1: Insulin-like growth factor-1; CS: Cervical stages; CVM stage: Cervical vertebrae maturation stage; IAP: Indian Association of Paediatrics; BMI: Body mass index; ELISA: Enzymelinked immunosorbent assay; ANOVA: Analysis of variance; LSD post hoc: Least significant difference post hoc test; SPSS: Statistical Package for the Social Sciences

\section{Acknowledgements}

The authors acknowledge the help of Dr. Rais Ahmed and Dr. Sabari Karthick in completing the study.

\section{Consent to participate}

Informed consent was obtained from each subject before beginning the study.

\section{Authors' contributions}

V.A: conceptualization, methodology, investigation, writing-original draft preparation, software.

A.N: software, visualization, writing-reviewing and editing

P.T: visualization, investigation.

G.K.S: Supervision.

G.P.S: software, validation.

A.A.M: writing - reviewing and editing, supervision.

All the authors read and approved the final manuscript.

\section{Funding}

The work was supported with the research grant under the Intra-Mural Research project by the Research Cell, King George Medical University, Lucknow, Uttar Pradesh, India.

\section{Availability of data and materials}

As a corresponding author, I have full access to all the data of this study and final responsibility for the decision to submit for publication

\section{Ethics approval and consent to participate}

Ethical approval was obtained from the institutional ethical committee,

Research Cell, King George Medical University, Lucknow, Uttar Pradesh, India. The ethical approval number of the study is 72nd ECM II-B-IMR/P2

\section{Consent for publication}

No photograph of the patient is used in this study.

\section{Competing interests}

All the authors declare that they have no competing interests. 


\section{Author details}

'Department of Dentistry, All India Institute of Medical Sciences, Bhubaneswar, Odisha 751019, India. ${ }^{2}$ Department of Orthodontics and Dentofacial Orthopaedics, King George's Medical University, Lucknow, UttarPradesh 226003, India. ${ }^{3}$ Department of Biochemistry, King George's Medical University, Lucknow, Uttarpradesh 226003, India. ${ }^{4}$ Tamilnadu, India.

Received: 21 February 2020 Accepted: 6 May 2020

Published online: 22 June 2020

\section{References}

1. Fishman LS. Radiographic evaluation of skeletal maturation. A clinically oriented method based on hand-wrist films. Angle Orthod. 1982;52:88-112.

2. Franchi L, Baccetti T, McNamara JA Jr. Mandibular growth as related to cervical vertebral maturation and body height. Am J Orthod Dentofacial Orthop. 2000;118:335-40.

3. Jang JC, Fields HW, Vig KW, Beck FM. Controversies in the timing of orthodontic treatment. Semin Orthod. 2005;11(3):112-8.

4. Baccetti T, Franchi L, Toth LR, McNamara JA Jr. Treatment timing for Twinblock therapy. Am J Orthod Dentofacial Orthop. 2000;118(2):159-70.

5. Ngan P. Early timely treatment of class III malocclusion. Semin Orthod. 2005; 11(3):140-5.

6. Kim JH, Viana MA, Graber TM, Omerza FF, BeGole EA. The effectiveness of protraction face mask therapy: a meta-analysis. Am J Orthod Dentofacial Orthop. 1999;115(6):675-85.

7. Malmgren O, Ömblus J, Hägg U, Pancherz H. Treatment with an orthopedic appliance system in relation to treatment intensity and growth periods. A study of initial effects. Am J Orthod Dentofacial Orthop. 1987;91(2):143-51.

8. Björk A, Helm S. Prediction of the age of maximum puberal growth in body height. Angle Orthod. 1967;37:134-43.

9. Hassel B, Farman AG. Skeletal maturation evaluation using cervical vertebrae. Am J Orthod Dentofacial Orthop. 1995;107:58-66.

10. Masoud M, Masoud I, Kent RL Jr, Gowharij N, Cohen LE. Assessing skeletal maturity by using blood spot insulin-like growth factor I (IGF-I) testing. Am J Orthod Dentofacial Orthop. 2008;134(2):209-16.

11. Hussain MZ, Talapaneni AK, Prasad M, Krishnan R. Serum PTHrP level as a biomarker in assessing skeletal maturation during circumpubertal development. Am J Orthod Dentofacial Orthop. 2013;143(4):515-21.

12. Tomei E, Sartori A, Nissman D, Al Ansari N, Battisti S, Rubini A, et al. Value of MRI of the hand and the wrist in evaluation of bone age: preliminary results. J Magn Reson Imaging. 2014;39(5):1198-205.

13. Baccetti T, Franchi L, McNamara JA Jr. The cervical vertebral maturation (CVM) method for the assessment of optimal treatment timing in dentofacial orthopedics. Semin Orthod. 2005;11:119-29.

14. Gupta S, Jain S, Gupta P, Deoskar A. Determining skeletal maturation using insulin-like growth factor I (IGF-I) test. Prog Orthod. 2012;13:288-95.

15. Perinetti G, Baccetti T, Contardo L, Di Lenarda R. Gingival crevicular fluid protein content and alkaline phosphatase activity in relation to pubertal growth phase. Angle Orthod. 2012;82:1047-52.

16. Hizuka N, Takano K, Tanaka I, Asakawa K, Miyakawa M, Horikawa R, et al. Demonstration of insulin-like growth factor I in human urine. J Clin Endocrinol Metab. 1987:64:1309-12.

17. Masoud MI, Masoud I, Kent RL Jr, Gowharji N, Hassan AH, Cohen LE. Relationship between blood-spot insulin-like growth factor 1 levels and hand-wrist assessment of skeletal maturity. Am J Orthod Dentofacial Orthop. 2009;136:59-64.

18. Ishaq RA, Soliman SA, Foda MY, Fayed MM. Insulin-like growths factor I: a biologic maturation indicator. Am J Orthod Dentofacial Orthop. 2012;142(5):654-61.

19. Jain S, Jain S, Deoskar A, Prasad VS. Serum IGF-1 levels as a clinical tool for optimizing orthodontic treatment timing. Prog Orthod. 2013;14(1):46(1-7).

20. Seminara SB, Messager S, Chatzidaki EE, Thresher RR, Acierno JS Jr, Shagoury JK, et al. The GPR54 gene as a regulator of puberty. Obstet Gynecol Surv. 2004:59(5):351-3.

21. Auchus RJ, Rainey WE. Adrenarche-physiology, biochemistry and human disease. Clin Endocrinol. 2004:60(3):288-96.

22. Frank GR. Role of estrogen and androgen in pubertal skeletal physiology. Med Pediatr Oncol. 2003;41(3):217-21

23. Labrie F, Bélanger A, Cusan L, Gomez JL, Candas B. Marked decline in serum concentrations of adrenal C19 sex steroid precursors and conjugated androgen metabolites during aging. J Clin Endocrinol Metab. 1997;82(8):2396-402.
24. Kroboth PD, Salek FS, Pittenger AL, Fabian TJ, Frye RF. DHEA and DHEA-S: a review. J Clin Pharmacol. 1999:39(4):327-48.

25. Chiu KM, Keller ET, Crenshaw TD, Gravenstein S. Carnitine and dehydroepiandrosterone sulfate induce protein synthesis in porcine primary osteoblast-like cells. Calcif Tissue Int. 1999;64(6):527-33.

26. Khadilkar V, Yadav S, Agrawal KK, Tamboli S, Banerjee M, Cherian A, et al. Revised IAP growth charts for height, weight, and body mass index for 5-to 18-year-old Indian children. Indian pediatrics. 2015;52(1):47-55.

27. World Health Organization. WHO guidelines on drawing blood: best practices in phlebotomy. World Health Organization; 2010.

28. Srinivasan B, Premkumar S. Assessment of serum dehydroepiandrosterone sulphate in subjects during the pre-pubertal, pubertal, and adult stages of skeletal maturation. Eur J Orthod. 2012;34(4):447-51.

29. Apter D, Pakarinen A, Hammond GL, Vihko R. Adrenocortical function in puberty serum ACTH, cortisol and dehydroepiandrosterone in girls and boys. Acta Paediatrica. 1979;68(5):599-604

30. Sulcova J, Hill M, Hampl R, Starka L. Age and sex related differences in serum levels of unconjugated dehydroepiandrosterone and its sulphate in normal subjects. J Endocrinol. 1997:154(1):57-62.

31. I Allemand D, Schmidt S, Rousson V, Brabant G, Gasser T, Gruters A. Associations between body mass, leptin, IGF-I and circulating adrenal androgens in children with obesity and premature adrenarche. Eur J Endocrinol. 2002;146(4):537-43.

32. SizoNenko PC, Paunier L. Hormonal changes in puberty III: Correlation of plasma dehydroepiandrosterone, testosterone, FSH, and LH with stages of puberty and bone age in normal boys and girls and in patients with Addison's disease or hypogonadism or with premature or late adrenarche. J Clin Endocrinol Metab. 1975;41(5):894-904.

\section{Publisher's Note}

Springer Nature remains neutral with regard to jurisdictional claims in published maps and institutional affiliations.

\section{Submit your manuscript to a SpringerOpen ${ }^{\circ}$ journal and benefit from:}

- Convenient online submission

- Rigorous peer review

- Open access: articles freely available online

High visibility within the field

- Retaining the copyright to your article

Submit your next manuscript at $>$ springeropen.com 